\title{
Engaging patients with "medically unexplained symptoms" in psychological therapy: An integrative and transdiagnostic approach
}

Short title: Therapeutic engagement of patients with MUS

Dr Janet Balabanovic ${ }^{\star 1}$ and Dr Philip Hayton ${ }^{1}$

${ }^{1}$ Professional Doctorate in Counselling Psychology programme, London Metropolitan University, London, UK

${ }^{*}$ Corresponding author information: Dr Janet Balabanovic, Chartered Counselling Psychologist, Pain Management Centre, National Hospital of Neurology and Neurosurgery, 25 Cleveland Street, London W1T 4AJ, England, e-mail: i.balabanovic@nhs.net.

\section{Abstract:}

Objectives: Patients with "medically unexplained symptoms" or "MUS" experience subjectively compelling and distressing somatic symptoms that are not fully explained by underlying physical pathology. Effective treatment of these patients has been impeded by multiple barriers. Problems with patient engagement have been highlighted in the clinical and research literature, yet few exploratory studies have been conducted in this area. This research explores how experienced psychological therapists in a specialist MUS service work to engage these patients.

Design: An in-depth qualitative study was conducted to explore the process of engaging patients with MUS in psychological therapy. 
Method: Semi-structured depth interviews were conducted with psychological therapists who work with complex patients with MUS. The therapists interviewed were recruited from an NHS primary care psychological therapy service that specialises in working with this patient group. Data were analysed using grounded theory to develop a model of this process.

Results: The analysis identified how multiple interacting layers of systemic, interpersonal and intra-psychic disconnections impede engagement. The research introduces a new theoretical framework "Negotiating disconnection" that conceptualises the process of engagement in terms of a series of stages: "Drawing in" (negotiating systemic disconnection), "Meeting" (connecting in the disconnection) and "Nudging Forward" (cultivating new connections) and illustrates how these are negotiated by therapists.

Conclusions: The model shows that it is critical for therapists to collaborate closely with GPs to engage these patients while also highlighting barriers to doing this, reflecting the complexities of organisational and cultural change. Clinically, the model illustrates the importance of adopting a flexible, pluralistic and integrative approach that is person and process-led. Doctors and therapists should embrace a holistic, biopsychosocial stance towards MUS and be sensitively attuned to its complex phenomenology. 


\section{Practitioner Points}

- To engage patients with MUS psychological therapists should be person and process-led rather than theory or protocol-led. A pluralistic and integrative mindset facilitates this by enhancing clinicians' flexibility.

- A multi-disciplinary approach is essential. Clinicians should embrace a biopsychosocial stance towards MUS and work closely with medical colleagues to help them do the same.

- Structural and cultural change is needed to tackle this issue effectively.

\section{Keywords:}

Therapeutic engagement, medically unexplained symptoms, grounded theory, qualitative, integration

\section{Acknowledgements:}

The authors are very grateful to the service that hosted this research and to the participating clinicians who gave their time and shared their experiences so openly.

\section{Introduction}

"Medically unexplained symptoms" (or "MUS") is a generic term that refers to a broad range of overlapping and poorly understood conditions involving persistent, subjectively compelling, and distressing somatic symptoms not explained by underlying medical illness (Brown, 2006). Experts concur that it most likely reflects a complex interaction between multiple aetiological factors, including both biological 
and psychosocial influences (Brown, 2007). Unhelpfully for this patient group, competing classification systems in psychiatry and medicine perpetuate a false dichotomy of "mind" versus "body" disorders which sits uneasily with a biopsychosocial framework (Strassnig, Stowell, First \& Pincus, 2006).

Since the early 1980s there has been a growth in cognitive-behavioural and information processing models of MUS (Brown, 2006; Deary, Chalder \& Sharpe, 2007; Rief \& Broadbent, 2007). Meanwhile, parallel interdisciplinary research has implicated chronic stress in these conditions (Rubin \& Wessely, 2006). More recently, attention has shifted to the role of emotional dysregulation, creating links with contemporary psychodynamic approaches emphasising the developmental origins of this (e.g. Fonagy, Gergely, Jurist \& Target, 2002). Growing evidence links MUS with problems in affect regulation, interpersonal functioning and stress system dysfunction (Luyten, van Houdenhove, Lemma, Target, \& Fonagy, 2012).

Historically, patients with MUS have been managed by medical professionals and psychological input has been variable (Fink, Burton, De Bie, Söllner, \& Fritzsche, 2011). Many have struggled in a dualistic health system, feeling dismissed by medical professionals yet reluctant to engage with mental health services (Gonzalez, Williams, Noël, \& Lee, 2005). Doctors in primary care have characterised patients with MUS as "difficult" and "frustrating" (Hahn, 2001), however, those lacking in empathy might actively contribute to the tension (Epstein et al., 2006). Often infused with conflict, the relationship has been characterised as a power struggle (e.g. Salmon, 2007). Dualistic attitudes fuel this opposition, leading patients to emphasise physical explanations for their symptoms. This preserves their sense of self as mentally well and protects them against mental health stigma. 
Patients with MUS are faced with a dilemma. With subjectively compelling somatic symptoms but no medical diagnosis, they experience a high level of uncertainty, confusion and frustration (Nettleton, 2006). Desperate for a definitive diagnosis, they may engage in "doctor shopping" (Dowrick, Ring, Humphris, \& Salmon, 2004). After a long history of fruitless investigations and treatments, they may feel misunderstood and stigmatised (Blom et al., 2012). Receipt of an "unexplained" diagnosis can lead to further distress and negative meaning, for example, that symptoms are "imagined, feigned or 'all in the mind" (Brown, 2007, p. 778).

It has been estimated that MUS costs the NHS in England £3 billion every year (Department of Health, 2011). Between $25-50 \%$ of somatic complaints seen in primary care are medically unexplained (Burton, 2003) and 10-15\% of these patients experience long term disability and suffering (Creed, Barksy \& Leiknes, 2011). Among this group, co-morbid personality, relationship, and physical health problems are common (Taylor, Mann, White, \& Goldberg, 2000). GPs are often left dealing with these most complex cases. Significant financial, political, \& logistical barriers have impeded development of effective MUS services (Henningsen, Fink, Hausteiner-Wiehle, \& Rief, 2011). However, recent developments are beginning to address the gap in service provision with the national expansion of "Integrated IAPT" and Liaison Psychiatry services (NHS England, 2016a). Improving Access to Psychological Therapies (IAPT) is primary care psychological therapy service that was launched nationally in the UK in 2006 to improve public access to evidencebased psychological therapies for depression and anxiety disorders. In 2016 the UK government announced plans to expand IAPT to offer psychological therapies to individuals who have long term conditions or medically unexplained symptoms alongside anxiety and depression. The term "Integrated IAPT" reflects the strategic 
vision that the newly expanded services should be closed integrated with physical health services.

Treatment approaches for MUS are relatively underdeveloped. Relatively few randomised controlled trials have been conducted for this patient group and the majority conducted have focused on CBT-based interventions (Kroenke, 2007). CBT models emphasise that MUS are precipitated and maintained by interacting biological, psychological and social processes. CBT is considered a useful approach for patients with MUS because it may help to circumvent dualistic debates and facilitate a non-judgmental and collaborative approach (Brown, 2007). Several contemporary psychodynamic approaches also seem promising, including Luyten and colleagues' DIT and embodied mentalization treatment model (Luyten et al., 2012) and Intensive Short-Term Dynamic Psychotherapy (ISDTP) which has been championed for MUS by Abbass (2005). These models emphasise the emotional and relational concomitants of MUS. For example, Abbass conceptualises MUS as the outcome of unconscious strivings to inhibit intense feelings and suggests that MUS symptoms can be ameliorated if patients can consciously experience the emotions that are creating conflict, triggering defence mechanisms and anxiety.

A recent meta-analysis of psychological therapies for MUS was published by (Kleinstäuber, Witthöft, \& Hiller, 2010). Although it examined all therapeutic modalities, the trials that met its strict inclusion criteria were mostly for CBT-related interventions. The meta-analysis concluded that CBT for MUS is modestly beneficial if delivered by a therapist who is experienced in working with this patient group. A growing number of studies have shown than third wave CBT approaches such as Acceptance and Commitment Therapy (ACT) (Hayes, 2004) may also have potential. ACT is a transdiagnostic and process-based therapy which fluidly weaves 
together didactic, experiential, and metaphorical elements and is known for its flexibility. Brassington et al. (2016) found that ACT can promote adjustment and improve quality of life for people struggling with physical symptoms. In addition to 'broad spectrum' CBT evidence, there is also some evidence for brief psychodynamic approaches. Several meta-analytic reviews have concluded that Short Term Dynamic Psychotherapies may be effective for patients who present with somatic symptoms (e.g. Abbass, Kisely, \& Kroenke, 2009) and there is accumulating evidence supporting ISTDP specifically (e.g. Abbass et al., 2010).

In the UK, healthcare treatments are guided by the National Institute for Health and Care Excellence (NICE), which produces guidelines based on rigorous analyses of treatment efficacy. Although there is evidence supporting both CBT and brief dynamic approaches for MUS, currently there are no NICE guidelines for psychological treatments for MUS apart from specific syndromes such as CFS and IBS. Given the modest effects of treatments evaluated to date, it seems that there is an urgent need for more effective treatments for MUS. Some authors (e.g. Witthöft \& Hiller, 2010) argue that future research should focus on integrative approaches. Irrespective of the treatment model, therapy for MUS can often fail early in the process due to engagement issues. Patients with MUS are often reluctant to accept referrals for therapy (Arnold, de Waal, Eekhof \& van Hemert, 2006) and early pilot work in IAPT found that therapists found it especially hard to engage these patients (de Lusignan et al., 2013). These findings are problematic given that somatic symptom improvement is predicted by positive initial expectations and active engagement (Timmer, Bleichhardt, \& Rief, 2006).

Research shows that doctors can strongly influence patients' motivation for treatments of all kinds (Di Blasi, Harkness, Ernst, Georgiou, \& Kleijnen, 2001). 
Chianello (2010) designed an enhanced GP consultation and referral script to address the key sensitivities of patients with MUS highlighted in the literature. In a simulation study, this script increased motivation to attend therapy with a medium effect size. Although engagement via GPs has been explored, very few qualitative studies have explored therapists' experiences working with patients with MUS. Luca (2011) explored the interventions that therapists employ when working with these patients. The study emphasised the "concrete" and "difficult and complaining" nature of these patients and their resistance to linking physical symptoms with psychological experiences. However, the research did not address the question of how therapists can work therapeutically in the context of these challenges.

The present research explores precisely this process drawing upon the experiences of psychological therapists who work in one NHS primary care therapy service that specialises in working with this patient group. Specifically, the research seeks to address the question of how the process of engagement unfolds and what therapists in the host service do to facilitate this.

\section{Method}

Overview: The exploratory and relational nature of this research topic called for an in-depth qualitative methodology. The aim was to elicit therapists' perspectives on how the process of engagement unfolds during therapy. A grounded theory (GT) method was selected as this approach is most explicitly oriented to understanding process and change (Willig, 2010). Uniquely, GT provides a set of procedures to help develop a theory about the process under investigation (Chamberlain, Camic, \& Yardley, 2003). The study aimed to create a theoretical framework for thinking about therapeutic engagement, with clear, practical relevance for clinical practitioners. 
Research context: The research was conducted in an inner London primary care psychotherapy service that works with patients with complex needs, including many patients with MUS. The service offers brief individual therapy and consultation services informed by psychoanalytic and systemic principles. The study was approved as a service evaluation study by the London-based NHS Trust associated with the service. Ethics approval was granted for the study by the London Metropolitan University Research Ethics Review Panel in February 2013. As this was a service evaluation the results were presented to the host service to share learnings with the team about effective engagement strategies used within the service.

Epistemology: In approaching this study, the researcher (author 1) embraced a realist constructionist stance (Elder-Vass, 2012) underpinned by a critical realist ontology (Bhaskar, 1998, 1975). From a constructivist epistemological perspective, the 'truth' or the meaning of a situation is inevitably influenced by the lens through which it is examined. Therefore, it is optimal to seek multiple perspectives and to use "triangulation" (Patton, 1999) to identify it, accepting that this is always provisional. Congruent with the researcher's epistemological stance, Strauss \& Corbin's GT approach was selected (Strauss \& Corbin, 1990, 1998; Corbin \& Strauss, 2015).

Participants: All the psychological therapists who worked in the host service were invited to take part in the study. The study was introduced through a presentation at a team meeting, followed by a formal email invitation. All invitees expressed a willingness to participate in principle, however ultimately, three therapists were unable to do so due to illness, maternity leave and conflicting travel plans. Semistructured depth interviews lasting approximately one-and-a-half hours were conducted with nine therapists from the service between August 2013 and January 2016. As recommended in GT, the sample of participants was relatively 
heterogeneous, although all participants worked in the same clinical context. The sample included a mix of psychologists and psychoanalytic psychotherapists, as shown in table 1.

Method: The researcher followed the GT method outlined by Strauss \& Corbin (Strauss \& Corbin, 1990, 1998; Corbin \& Strauss, 2015). Consistent with GT principles, data collection and analysis were interwoven throughout the process and the interview schedule was revised iteratively. The technique of "constant comparative analysis" (Glaser \& Strauss, 1967) was pursued throughout the study to compare data within and between participants and across incidents to understand the context and to elucidate the key processes involved in engagement. Data analysis was conducted with the support of NVivo 10 qualitative analysis software. In line with the researcher's doctoral programme, an abbreviated version of GT was used (Willig, 2001). A full GT study was beyond the scope of a doctoral thesis in Counselling Psychology and was not essential to contribute to the literature. In full GT, data collection and analysis proceeds until theoretical saturation is reached, when nothing new is being contributed to the emerging theory (Glaser \& Strauss, 1967). However, in abbreviated GT, theoretical sufficiency is accepted as an adequate and appropriate intermediate objective (Dey, 1999).

The researchers: Author 1 conducted this study as part of her Professional Doctorate in Counselling Psychology and analysed the results with supervision from an experienced GT researcher and supervisor (author 2). Author 1 has significant experience working with patients with MUS in both primary care and hospital settings. Clinically, she embraces a pluralistic framework with respect to treatment modalities (Cooper \& McLeod, 2007) and a biopsychosocial approach to health and illness (Engel, 1977, 1982). 
Analytical process: All interviews were audio-recorded with participants' consent and transcribed verbatim by the researcher. The analytical process began with open coding as soon as the first interview had been transcribed (Strauss \& Corbin, 1998). Author 1 read each transcript line-by-line, breaking the data into individual meaning units, and labelled them with initial codes indicating the referent concept. Where relevant, she tried to embed action in the codes (Charmaz, 2006; Glaser, 1978). After completing stage one open coding for the first five interviews, initial codes were compared and clustered to construct low-level descriptive concepts. Axial coding (Strauss, 1987) was introduced to differentiate between "context" and "process" and to explore the links between the emerging concepts. As described by Corbin \& Strauss, 2015, p. 158-159), axial coding involved systematically exploring "conditions", "actions/interactions" and "consequences" to identify these links. The above processes were repeated until the highest-level theoretical categories were constructed and an initial model was developed. Where possible, "in-vivo" concepts were constructed using language relevant to the setting to help bring the data to life (Charmaz, 2006). In stage two more data was collected and selective coding (Strauss \& Corbin, 1998) was used to refine and integrate the categories to construct the model. This included constructing the emergent core category to pull all the underlying categories together into a coherent framework. Overall, the analytical process took approximately 6 months, including 3 months of analysis after stage 1 and stage 2 interviews respectively.

Establishing rigour: A variety of processes were conducted to establish analytical rigour throughout the study. Author 1's open coding was reviewed in detail by author 2 to ensure that the initial codes made sense in relation to the underlying data. Throughout the study verbal and visual or diagrammatic memos were constructed to 
capture the emerging analytical process (Charmaz, 2006). An audit trail was maintained to document the construction of the concepts and the development of the initial model (Lincoln \& Guba, 1985). As a validity check, both the analytical memos and the audit trail were reviewed by author 2 to ensure "reasonableness" (Elliott, Fisher \& Rennie, 1999). Selected quotations have been included in the results to illustrate the grounding of the analysis.

\section{Results of analysis}

The conceptual model derived from this research provides a framework for understanding the process of therapeutic engagement of patients with MUS and how clinical practitioners in the host service seek to address this. The model is depicted graphically in figure 1. It contains seven high-order categories which are listed in table 2. Categories 1-4 specify the unique contextual factors underlying this process ("context") and categories 5-7 address the stages of the engagement process ("process"). Above these lies the core category "negotiating disconnection" which integrates the seven higher-order categories within the model. The sections below provide a summary of the major categories of the model. A more detailed exposition of the model can be found in author 1's doctoral thesis (Reference withheld).

\section{Exploring the context of therapeutic engagement (categories 1-4)}

This section introduces the first four categories, which together, define the unique context of this research.

Category 1 'Primary care system orientation to MUS': Therapists perceived that GPs have a central role to play in managing patients with MUS in primary care. However, they can really struggle to manage these patients, and may, themselves, 
unwittingly contribute to engagement difficulties. For patients with severe and chronic MUS, there may be a long history of difficulties in the GP-patient relationship, including problematic dynamics of collusion or conflict. This can negatively impact a patient's perspective on their problem and their attitude to seeking help through the health system. Therapists suggested that GPs vary in how they handle the referral process in terms of sensitivity, transparency and clarity, influencing whether patients attend psychotherapy assessments, and how they present.

"Sometimes there can be a challenge where there is a GP who has tried everything, who feels frustrated with the patient,...., and then you get a referral for someone who isn't expecting to see a psychologist, and doesn't know why they have been referred." ('John', 224-226)

Category 2 'Service orientation to MUS': This category illustrates the characteristics of the service context that are most crucial with respect to engagement, including the service's specialist positioning, its accommodating policies and procedures and its psychoanalytic and systemic orientation. Therapists stated that the service remit is to work with "hard-to-engage" patients and all had significant prior experience working with other hard-to-engage groups. They noted that the service has embraced a range of accommodating policies and procedures designed specifically to promote engagement, including flexible referral and discharge procedures, proactive engagement efforts, and systemic and partnership working. Reflecting the psychoanalytic service culture, therapists tended to gravitate to emotional and relational understandings of MUS, which may be helpful providing that this is gently and sensitively negotiated with patients. 
“They're a lot more flexible than other services in terms of discharge and referrals, eh, acceptance thresholds, which is necessary because MUS patients don't think they have a problem. ..., having that extra bit of flexibility and liaison with the GPS enables us to get a lot more in.” ('Rebecca', 465-469)

Category 3 'Patient orientation to therapy for MUS': Therapists suggested that patients' attitudes towards their symptoms and their emotional and relational functioning may create multiple interacting barriers to engagement. The most pertinent factor highlighted was patients' beliefs about the nature of their symptoms and their possible relationship with psychological factors. Depending on their beliefs, patients may experience strong negative emotional reactions in response to a referral for psychological therapy. Therapists considered the valence and intensity of these reactions and patients' willingness to be open about these feelings to be important influences on engagement. Underlying emotional and relational issues were also seen to present barriers to the formation of a therapeutic relationship, depending on the severity of these issues. Therapists reported that these issues may also contribute to therapy sabotaging behaviours that need to be managed, such as excessively passive behaviour or getting stuck in "body-talk", that is, talking exclusively about bodily symptoms and avoiding psychosocial issues. Finally, the most complex patients may exhibit psychological deficits thought to be related to severe and chronic MUS, such as alexithymia and/or mentalising difficulties, creating further barriers to engagement.

"Often, the patients with medically unexplained physical symptoms are the ones who find it more difficult to mentalise, you know, to reflect on experiences psychologically, 
so that experiences are more likely to be expressed or discharged through the body." ('Freya', 357-359)

Category 4 'Therapist orientation to therapy for MUS': Therapists construed engagement as a stage-like process, including three key stages: "initial attendance" (getting patients to attend and complete a psychosocial assessment), "initial engagement" (building a positive therapeutic alliance) and "real engagement" (engaging patients effectively in the process of therapy itself). These stages framed the structure of the model and its conceptual core. The analysis also showed that therapists varied in their orientation to the different stages of engagement in terms of their motivations, priorities and their own anxieties, influencing their personal effectiveness at negotiating these different stages. Based on therapists' accounts of their behaviours in therapy and the ensuing reactions of their patients, various dimensions of difference seemed to be most relevant to the process of engagement. Therapists who had more experience working with MUS showed a cultivated sensitivity to MUS-related experiential phenomena and seemed to capitalise on this knowledge to build a strong therapeutic alliance. Despite their preferences for psychodynamic ways of working, the analysis indicated that therapists improved their engagement success when they adopted a more person-centred and process-led approach. Indeed, many therapists recalled learning from experiences of "losing patients" on occasions where they had been too theory and task-led in their approach. Therapists also described embracing a holistic understanding of their patients' difficulties to improve engagement, however, "tacit dualism" was very occasionally in evidence. In these moments, therapists temporarily "psychologised" their patients' symptoms and lost sight of their physical suffering, leading to therapeutic ruptures. 
"I can think of one case in particular of a girl with a mysterious (physical symptom) .... She'd had a psychotic mother and I think I talked about, sort of, the bit of her body that had gone mad, like this sort of mum who was inside her. And I think it was a bit over-zealous......she just didn't get it.... It didn't make sense to her." ('John', 362-365)

\section{Analysis of context: The dilemma of disconnection}

In GT it is necessary to identify participants' core concern (Glaser, 1998). In this study, the process of constant comparison across and within categories 1-4 gradually seemed to point towards the notion of disconnection as a permeating theme, which eventually became central to the model. The disconnections were broad-ranging and operated at different levels, constituting multiple interacting barriers to engagement. Disconnections were organisational (reflecting the dualistic structure of the health system), interpersonal (disconnections between patients and GPs, patients and therapists, and therapists and GPs) and intrapersonal or intrapsychic (for example, patients who are disconnected from their emotions, or who fail to link somatic sensations with emotional experiences). Although issues of disconnection were multi-faceted and interacting, a fundamental aspect of disconnection related to discrepant beliefs regarding the nature and causes of MUS symptoms. As highlighted in category 3, patients with MUS seen in this service often held strong beliefs that they were physically ill, however category 2 suggests that the therapists often drew on psychoanalytic frameworks that seek to explain MUS in terms of its causal origins, rooted in emotional or relational disturbances. In this context, therapy brings together two parties who may view a problem from very different perspectives and may have diverging concerns and priorities. 


\section{Exploring the unfolding process of engagement (categories 5-7)}

The remaining categories of the model outline the core behavioural strategies employed by therapists to negotiate disconnections through the three stages of engagement previously identified, as summarised below.

\section{Category 5 'Drawing in' (Drawing-in patients by engaging the system):}

"Drawing in" highlights the activities that are oriented towards the task of getting MUS patients to attend and complete an assessment (stage 1: initial attendance). The analysis suggested that therapists try to do this by negotiating disconnections within the health system. They did this by striving to form strong, collaborative working relationships with GPs, by working with GPs to improve the referral process, and by providing emotional support, case consultation, and formal training to support GPs. However, their accounts suggested that they must be proactive in nurturing these relationships as GPs are not always able to respond to participants' efforts to engage with them due to pressures within the primary care system.

"GPs can be quite harsh in their burnt out states, saying that they're crazy. So you just have to validate that first of all, and then, um, ... give your thoughts about what might be going on and why they (the patient) are acting like that." ('Rebecca', 493495)

Category 6 'Meeting' (Meeting patients where they're at): This category incorporates the behavioural strategies that therapists described using to promote a positive therapeutic alliance with patients with MUS (stage 2: initial engagement). To promote initial engagement, therapists expressed a need to engage with the subjective experience of their patients, including their preoccupation and distress with their physical symptoms. They described striving to form an emotional 
connection with patients and using specific strategies to do this if patients seem disconnected from their own emotions. However, they also emphasised the need to tap into hidden communications, via transference and countertransference phenomena, to construct hypotheses about unconscious emotional or relational factors that may be linked with the patients' difficulties. Most importantly, therapists stressed the importance of adapting flexibly to each individual patient to find a helpful focus for the work, which was not always about insight. Reflecting the service's focus on hard-to-engage patients, therapists attended carefully to initial engagement barriers, especially relational barriers, and tried to address these barriers with great sensitivity and empathy. Perhaps most crucially, they emphasised the need for exceptional sensitivity when sharing formulation ideas, especially initial formulations. Holding in mind multiple levels of formulation, they always considered digestibility when choosing whether, how, and when to share these ideas with patients.

"A lot of these patients won't really elaborate a great deal on their relationships or on their emotional life, .... you're very much thrown back on working with um what's in the room, ......and um what links might we make between that and what they're telling me about their physical symptoms.” ('Freya', 642-646)

\section{Category 7 'Nudging forward' (Nudging patients to think about both the mind} and the body and the links between them): This category illustrates how therapists work to engage patients in the process of therapy itself (stage 3: "real engagement"). Therapists described employing active strategies to foster body-mind links through psycho-education and exploring the antecedent context of somatic symptoms in and outside the therapy session. They indicated that they tended to use simple, tentative interpretations to help patients cultivate connections between their 
MUS symptoms and unprocessed emotional or relational experiences. They try to maintain an optimal degree of tension by pacing the work carefully and balancing the expression of empathy and validation with appropriate confrontation. They also described attending to process issues and self-sabotaging behaviours that may impede therapy, such as repetitive body talk. Finally, they described managing therapeutic impasse constructively by adjusting their approach, for example, by switching from insight work to symptom self-management, or to systemic work to help patients improve functioning in their external world.

"I think all therapeutic work is, but with these patients, it is about trying to move people forward but not being, you know, too much too soon. And you're somehow trying to negotiate this, kind of, middle position, ... I mean you don't want to be so probing so soon that the patient will withdraw, but you have to be a bit probing in order to be effective." ('Freya', 550-558)

The emergent core category: Negotiating disconnection: According to Strauss \& Corbin, a key step in theoretical integration is to locate a super-ordinate core category that represents what the research is all about. Following the theme of disconnection, the model contributes to understanding therapeutic engagement of patients with MUS by conceptualising this as a process of "negotiating disconnection", the emergent core category for this study. As an abstract theoretical construct this core category integrates all the major categories of the model and provides a framework for understanding why and how therapists approach the task of engagement the way they do. The concept of negotiation was invoked because this is a very complex process bringing together multiple parties whose roles, needs, beliefs and motivations may not always be closely aligned. 


\section{Discussion \& Conclusions}

The challenge of engaging patients with MUS in psychological therapy is a highly pertinent practice-based issue that has not been addressed in previous research. In line with the aims of practice-based research (McLeod, 2001), this study has synthesised the experience of therapists who have significant expertise working with this patient group to help shed light on this process. Given the current impetus to expand psychological services for these patients through "Integrated IAPT", the research is very timely and relevant.

The central aim of GT is to create an abstract theoretical framework representing a social-psychological process. This study explored how participants themselves defined therapeutic engagement and the resulting model is novel in its broad conceptualisation of this process. The core category constructed "negotiating disconnection" conceptualises the process of engagement in terms of a series of stages: "drawing in" (negotiating systemic disconnection to promote initial attendance), "meeting" (connecting in the disconnection to promote initial engagement), and "nudging forward" (cultivating connections to promote real engagement in the process of therapy), and illustrates how the different stages of engagement are negotiated by therapists. Meeting Glaser's requirements of "relevance" and "grab" (Glaser \& Strauss, 1967), these may be helpful concepts for therapists to hold onto in their work with these patients.

The research indicates that disconnection seems to be the core dilemma faced by therapists during the engagement process. There is a fundamental disconnect between how patients and therapists understand the patients' symptoms. However, disconnection is also mirrored in GP's relationships with patients, which can be 
fraught with tension and misunderstanding. Therapists also struggle with disconnection from GPs due to structural problems in the health system, particularly the entrenched split between physical and mental health services. The challenge for therapists and services is to negotiate the layers of disconnection present in the system, the therapeutic process, and the client's presenting issues. These powerful psychological, sociocultural, economic and political forces make this negotiation very difficult, explaining why the challenge of improving services for patients with MUS has been so intractable historically.

Although conducted in a setting that is strongly influenced by psychoanalytic and psychodynamic ideas, a key finding of the research is that practicing in a pure psychodynamic way is generally not engaging for many patients with MUS. Participants turned to psychoanalytic and psychodynamic theories to understand and conceptualise challenging relational dynamics. However, they most often pursued a person- and process-orientated, and more collaborative approach to engage patients, frequently adopting behavioural and systemic interventions alongside insight work.

Initial attendance: "Drawing in" illustrates that therapists negotiate structural and relational disconnections within the system by proactively developing strong, collaborative working relationships with GPs, to help patients complete psychological assessments. Echoing previous research (Fischhoff \& Wessely, 2003), GPs seem to vary in the degree to which they think in psychologically informed ways about their patients. Problematic GP-patient relationships or poorly managed referrals may mean that patients who could potentially benefit from therapy never make the first step or arrive at therapy confused or frustrated. Although co-location of psychological and medical care seems to help, the model suggests that this does not necessarily 
address all elements of disconnectedness. Some GPs may be unwilling or unable to commit the time required for effective inter-professional working. Similarly, therapists may vary in their interest, willingness and confidence to proactively address systemic disconnection. Disconnection may also be exacerbated by health professionals' roles, cultural norms within work settings, and staff selection and training.

Initial engagement: The model illustrates that "initial engagement" of complex patients with MUS can be fraught with barriers that may create disconnection between therapists and patients. Patients can present as angry, dismissive or ambivalent about the referral, have rigid beliefs about their illness, or be fixated on locating the assumed organic cause. Early relational trauma may create deeply embedded relational anxieties and use of unconscious defence mechanisms, such as defensive body-talk, to keep the therapist at a distance. Intra-psychic disconnection between different parts of the patient can create further barriers. For example, some patients with MUS can be disconnected from their emotional experience, consistent with reports that they tend to "stuff" their feelings (Bakal, Coll, \& Schaefer, 2008). Others may be aware of their feelings but fail to link them with bodily sensations, reflecting highly specific embodied mentalising deficits (Luyten et al., 2012). In short, therapists may have to navigate a complex web of conscious and unconscious intra-psychic and interpersonal disconnections to form a positive therapeutic alliance. "Meeting patients where they're at" shows that to do this effectively, therapists need to be highly attuned to patients' sensitivities, flexible and adaptable, and prepared to deal with challenging dynamics. It seems that therapists facilitate initial engagement when they go with patients' bodily preoccupation, validate their challenging health(care) experiences, and position therapy as a treatment to help patients cope with MUS symptoms. Signalling that patients' 
symptoms are being taken seriously, these strategies may address issues of illegitimacy (Nettleton, 2006), and reduce defensiveness (Kirmayer, Groleau, Looper, \& Dao, 2004).

This way of working may create tension for some psychodynamic therapists. Less experienced or flexible therapists may be over-zealous in encouraging patients to talk about their childhood or relational experiences before patients understand or accept the rationale for doing so. Despite increasing acceptance of the biopsychosocial nature of MUS (Luyten, Van Houdenhove, Lemma, Target, \& Fonagy, 2013), participants occasionally doubted the veracity of their patients' physical complaints. Therapeutic ruptures can easily occur if patients detect overt or tacit dualistic beliefs in therapists and conclude that their symptoms are being "psychologised". Therapists must identify and address these ruptures quickly and sensitively to avoid early disengagement (Katzow \& Safran, 2007). More complex patients may maintain distance or devalue therapy or the therapist. To connect with these patients in their state of disconnection, therapists may need to work hard to pick up emotional undercurrents that are not consciously experienced or expressed by the patient, by attending to transference and countertransference and non-verbal communications. By exploring these barriers openly with the patient, therapists may be able to pre-emptively and proactively address relational barriers that could undermine engagement.

Real engagement: "Nudging forward" suggests that therapists can promote real engagement in the process of therapy by nudging patients forward gradually to help them cultivate new connections, offering them new ideas to consider, and gently pushing or supporting them if process difficulties or skills deficits are encountered. In many cases, this may mean moving away from insight towards skills building or 
helping patients to cultivate better connections in their external world. Engagement may be promoted when therapists are able to work at the edge of their patient's comfort zone, providing well-timed, digestible input that is within their grasp. To work "in the zone", the research suggests that therapists need to be attuned to their patient's psychological awareness and functioning (e.g. their mentalising capacity), emotional arousal, and the moment-to-moment quality of the therapeutic relationship and adjust their interventions accordingly. A parallel could usefully be drawn with developmental concepts such as the zone of proximal development (Vygotsky, 1978), and of scaffolding (Wood, Bruner \& Ross, 1976). Addressing the intra-psychic body-mind split was seen as a central goal of therapy for many patients with MUS. Participants highlighted the power of working "in the room" to help patients make these links. This makes intuitive sense for complex patients presenting with MUS who are prone to ignoring their body, thereby missing signs of emotional distress (Bakal, Coll, \& Schaefer, 2008). This is also consistent with ISTDP, which promises to alleviate MUS by helping patients to experience the emotions that are creating conflict, triggering defence mechanisms and anxiety (Abbass, 2005).

\section{Implications}

Service development: This study highlights that more integrated service models can help promote MUS patient engagement, however, there is a chasm between the strategic vision of integration and the reality of implementation. It seems that the split functions of physical and mental health are very strongly embedded in our system. Strong service leadership will be essential to "rock the boat" and challenge traditional service structures and working practices, roles and responsibilities. The study indicates that GPs can help patients with MUS to engage in psychological therapy, 
however, more training is required to support this. Useful training topics could include patient selection, referral timing and positioning, sensitive communication with MUS patients, and managing challenging GP-patient dynamics. Yon et al. (2017) explored this issue and concluded that there is an urgent need to improve training on MUS for newly qualified doctors as current provision is very limited. Similar training could also greatly benefit health professionals working in secondary care hospital settings. Recent research suggests that the way doctors manage patients with MUS in secondary care is highly variable and that they have little or no formal training in this area (Warner, Walters, Lamahewa, \& Buszewicz, 2017).

Psychological treatment provision: At present, NICE guidelines for psychological treatments for MUS are limited. As a result, there is a need for creativity and innovation and more research to generate more effective treatments. Notably, Integrated IAPT funding was offered for MUS treatments based on "comprehensive assessment and formulation followed by therapy broadly based on CBT principles" (NHS England, 2016b). This is a welcome development, providing permission for case formulation-guided, rather than protocol-driven therapy. This study suggests that treatment models emphasising coping may be more palatable to MUS patients, promoting initial attendance and engagement. The present model suggests that therapists help patients make sense of their symptoms in an iterative way allowing space for the patient's own narrative to feed into this. This is compatible with a CBT framework, which can be used flexibly to co-construct a shared understanding of the problem (de Lusignan et al., 2013). The fact that flexibility and adaptability promote engagement reinforces the value of transdiagnostic CBT approaches to MUS, such as ACT. ACT fluidly weaves together didactic, experiential, and metaphorical elements and is known for its flexibility (Hayes, 2004). 
Therapist recruitment, training and supervision: Overall, the research illustrates the importance of adopting a flexible, person and process-oriented approach to engage patients with MUS in psychological therapy. However, many patients with MUS will now be seen in IAPT, which emphasises evidence-based and protocol-driven CBT therapies. A competency framework developed for staff working in the new Integrated IAPT services stipulated that staff should be taught at least one biopsychosocial model of MUS (Roth \& Pilling, 2015). However, this study suggests that a pluralistic, cross modality, mindset may be especially valuable for engaging these patients, allowing the therapist flexibility to focus attention on the patient's cognitive, behavioural, emotional and relational functioning, as needed. IAPT-trained therapists who work with patients with MUS might therefore also benefit from additional training to expand their understanding of MUS from different theoretical perspectives as this will enhance their clinical flexibility. This might include third wave process-based treatment approaches such as ACT (Hayes, 2004) or contemporary psychodynamic approaches to MUS, including ISTDP and DIT models (Abbass, 2005; Luyten et al., 2012). To enhance clinical sensitivity, therapists would also benefit from additional training on the physiological mechanisms of MUS (e.g. central sensitization), the phenomenology of MUS and the impact of socio-cultural factors on patients, including diagnosis, labelling, and the behaviour of healthcare professionals who refer these patients for psychological therapy. Finally, therapists should also be suitably prepared for inter-professional working. To support a process-focused way of working, expert clinical supervision is vital, ideally with therapists who have MUS expertise. Psychologists are well-suited to this role as they are trained in multiple therapeutic models (Health \& Care Professions Council, 2015).

\section{Critical evaluation and suggestions for future research}


This study had several methodological limitations. The chosen method relied on therapists' reports about their practice, not their actual behaviour. The constructivist epistemological stance means that the model developed is just one possible construction of the process. The capacity to engage in theoretical sampling was constrained by the limited pool of participants, so the output is perhaps best viewed as a "best fit model" based on the available data. The interviews were conducted over a very long time-frame which may have obscured any changes that could have occurred over time in the way that the therapists work.

As is typical in GT, the model was developed in a specific substantive setting, in this instance, a service that targets complex patients with MUS in primary care. The category or label MUS incorporates a large spectrum of diagnoses and therapists working in primary care must be prepared to deal with this heterogeneity. Reflecting this context, the study focused on the commonalities observed in the clinical process across different MUS presentations. However, the study's participants work with patients at the more complex end of the spectrum, so some features of the model may reflect complexity in general terms rather than features of MUS specifically. As this was a small-scale, abbreviated GT theory study conducted in a specific clinical setting, the author makes no claim that the findings are generalisable to other settings. Further research is needed among a large sample of participants across multiple settings to validate this model and to determine if it can be generalised to other settings or to related patient groups, such as patients with long term physical health conditions.

The study does not capture the patients' perspective on the issue of engagement. Qualitative studies of patients' treatment experiences can contribute valuably to improving clinical practice (Hodgetts and Wright, 2007), especially as there is often 
poor agreement between therapists and patients regarding therapeutic processes (Tryon, Blackwell \& Hammel, 2007). A qualitative study exploring therapeutic engagement from the patient's perspective would be an obvious, natural progression from this research. In such a study it might be possible to sample participants according to their level of engagement in treatment. This would provide a powerful basis for comparison to really elucidate which factors promote or inhibit engagement. Perhaps most informative would be exploratory research among patients who disengage from therapy or fail to take it up. Recruitment of such participants could prove very challenging. However, GPs could be engaged in the research recruitment process, as they maintain ongoing relationships with these patients. 


\section{References (author 1's thesis to be added)}

Abbass, A. (2005). Somatisation: Diagnosing it sooner through emotion-focused interviewing. The Journal of Family Practice, 54(3), 231-243.

Abbass, A., Campbell, S., Magee, K., Lenzer, I., Hann, G., \& Tarzwell, R. (2010). Cost savings of treatment of medically unexplained symptoms using intensive shortterm dynamic psychotherapy (ISTDP) by a hospital emergency department. Archives of Medical Psychology, 2(1), 34-44.

Abbass, A., Kisely, S., \& Kroenke, K. (2009). Short-term psychodynamic psychotherapy for somatic disorders: Systematic review of meta-analysis of clinical trials. Psychotherapy and Psychosomatics, 78(5), 265-274. doi:10.1159/000228247

Arnold, I. A., de Waal, M. W. M., Eekhof, J. A. H., \& van Hemert, A. M. (2006).

Somatoform Disorder in Primary Care: Course and the Need for Cognitive-

Behavioral Treatment. Psychosomatics: Journal of Consultation Liaison Psychiatry, 47(6), 498-503. doi:10.1176/appi.psy.47.6.498

Bakal, D., Coll, P., \& Schaefer, J. (2008). Somatic awareness in the clinical care of patients with body distress symptoms. BioPsychoSocial Medicine, 2. doi:10.1186/1751-0759-2-6

Bhaskar, R. (1975). A realist theory of science. Leeds: Leeds Books.

Bhaskar, R. (1998). The possibility of naturalism. London: Routledge.

Blom, D., Thomaes, S., Kool, M. B., van Middendorp, H., Lumley, M. A., Bijlsma, J. W. J., \& Geenen, R. (2012). A combination of illness invalidation from the work 
environment and helplessness is associated with embitterment in patients with FM. Rheumatology, 51(2), 347-353.

Brassington, L., Ferreira, N. B., Yates, S., Fearn, J., Lanza, P., Kemp, K., \& Gillanders, D. (2016). Better living with illness: A transdiagnostic acceptance and commitment therapy group intervention for chronic physical illness. Journal of Contextual Behavioral Science, 5(4), 208-214. doi:10.1016/j.jcbs.2016.09.001

Brown, R. J. (2006). Medically unexplained symptoms. In N. Tarrier (Ed.), Case formulation in cognitive behaviour therapy: The treatment of challenging and complex cases. (pp. 263-292). New York, NY: Routledge/Taylor \& Francis Group.

Brown, R. J. (2007). Introduction to the special issue on medically unexplained symptoms: Background and future directions. Clinical Psychology Review, 27(7), 769-780. doi:10.1016/j.cpr.2007.07.003

Burton, C. (2003). Beyond somatisation: a review of the understanding and treatment of medically unexplained physical symptoms (MUPS). The British Journal of General Practice, 53, 231-239.

Chamberlain, K., Camic, P., \& Yardley, L. (2003). Qualitative analysis of experience: grounded theory and case studies. In D. F. Marks \& L. Yardley (Eds.), Research Methods for clinical and health psychology (pp. 69-89). London: Sage.

Charmaz, K. (2006). Constructing grounded theory: A practical guide through qualitative research. London: Sage.

Chianello, T. (2010). Somatization and engagement in mental health treatment. Dissertation Abstracts International Section A: Humanities and Social Sciences, 
71(6-A), 2226.

Cooper, M., \& McLeod, J. (2007). A pluralistic framework for counselling and psychotherapy: Implications for research. Counselling \& Psychotherapy Research, 7(3), 135-143. doi:10.1080/14733140701566282

Corbin, J., \& Strauss, A. (2015). Basics of Qualitative Research: Techniques and procedures for developing grounded theory (Fourth Edition ed.). Los Angeles: Sage Publications, Inc.

Creed, F., Barksy, A., \& Leiknes, K. A. (2011). Epidemiology: prevalence, causes and consequences. In F. Creed, P. Henningsen \& P. Fink (Eds.), Medically unexplained symptoms, somatisation and bodily distress. (pp. 1-41). Cambridge: Cambridge University Press.

Deary, V., Chalder, T., \& Sharpe, M. (2007). The cognitive behavioural model of medically unexplained symptoms: A theoretical and empirical review. Clinical Psychology Review, 27(7), 781-797. doi:10.1016/j.cpr.2007.07.002

De Lusignan, S., Jones, S., McCrae, N., Cookson, G., Correa, A., \& Chan, T. (2013). IAPT LTC/MUS Pathfinder Evaluation Project Phase 1 Final report. Retrieved from http://www.iapt.nhs.uk/silo/files/ltcmus-pathfinder-evaluation--phase-1.pdf.

Department of Health (2011). No health without mental health. Retrieved from www.doh.gov.uk.

Dey, I. (1999). Grounding grounded theory: Guidelines for qualitative enquiry. London: Academic Press.

Di Blasi, Z., Harkness, E., Ernst, E., Georgiou, A., \& Kleijnen, J. (2001). Influence of 
context effects on health outcomes: a systematic review. Lancet, 357(9258), 757762.

Dowrick, C. F., Ring, A., Humphris, G. M., \& Salmon, P. (2004). Normalisation of unexplained symptoms by general practitioners: a functional typology. The British Journal Of General Practice: The Journal Of The Royal College Of General Practitioners, 54(500), 165-170.

Elder-Vass, D. (2012). Towards a realist social constructionism. Sociologia, Promblemas e Práticas, 70, 9-24.

Elliot, R., Fisher, C.T. \& Rennie, D.L. (1999). Evolving guidelines for publication of qualitative research studies in psychology and related fields. British Journal of Clinical Psychology, 38, 215-229.

Engel, G. L. (1977). The need for a new medical model: A challenge for biomedicine. Science, 196(4286), 129-136. doi:10.1126/science.847460

Engel, G. L. (1982). The biopsychosocial model: Extending the scope of scientific medicine. In L. J. West \& M. Stein (Eds.), Critical issues in behavioural medicine. (pp. 149-158). Toronto: J. B. Lippincott.

Epstein, R. M., Shields, C. G., Meldrum, S. C., Fiscella, K., Carroll, J., Carney, P. A., \& Duberstein, P. R. (2006). Physicians' responses to patients' medically unexplained symptoms. Psychosomatic Medicine, 68(2), 269-276. doi:10.1097/01.psy.0000204652.27246.5b

Fink, P., Burton, C., De Bie, J., Söllner, W., \& Fritzsche, K. (2011). Current state of management and organisation of care. In F. Creed, P. Henningsen, \& P. Fink (Eds.), 
Medically unexplained symptoms, somatisation and bodily distress: Developing better clinical services. (pp. 97-123). Cambridge: Cambridge University Press.

Fischhoff, B., \& Wessely, S. (2003). Managing patients with inexplicable health problems. British Medical Journal, 326(7389), 595.

Fonagy, P., Gergely, G., Jurist, E. L., \& Target, M. (2002). Affect regulation, mentalization, and the development of the self. New York, NY: Other Press.

Glaser, B. G. (1978). Theoretical sensitivity. Mill Valley, CA: The Sociology Press.

Glaser, B. G. (1998). Doing grounded theory: Issues and discussions. Mill Valley, CA: The Sociology Press.

Glaser, B. G., \& Strauss, S. A. (1967). Discovery of grounded theory. Strategies for qualitative research. New York: Aldine.

Gonzalez, J., Williams, J. W., Jr., Noël, P. H., \& Lee, S. (2005). Adherence to mental health treatment in a primary care clinic. The Journal Of The American Board Of Family Practice, 18(2), 87-96.

Hahn, S. R. (2001). Physical symptoms and the physician-experienced difficulty in the physician-patient relationship. Annals of Internal Medicine, 134, 894-904.

Hayes, S. C. (2004). Acceptance and Commitment Therapy and the New Behavior Therapies: Mindfulness, Acceptance, and Relationship. In S. C. Hayes, V. M. Follette, \& M. M. Linehan (Eds.), Mindfulness and acceptance: Expanding the cognitive-behavioral tradition. (pp. 1-29). New York, NY, US: Guilford Press.

Health \& Care Professions Council (2015), Standards of proficiency: Practitioner 
Psychologists. Retrieved from: http://www.hcpcuk.co.uk/publications/index.asp?id=198\#publicationSearchResults

Henningsen, P., Fink, P., Hausteiner-Wiehle, C., \& Rief, W. (2011). Terminology, classification and concepts. In F. Creed, P. Henningsen, \& P. Fink (Eds.), Medically unexplained symptoms, somatisation and bodily distress: Developing better clinical services. (pp. 43-68). Cambridge: Cambridge University Press.

Hodgetts, A., \& Wright, J. (2007). Researching clients' experiences: A review of qualitative studies. Clinical Psychology \& Psychotherapy, 14(3), 157-163. doi:10.1002/cpp.527

Katzow, A. W., \& Safran, J. D. (2007). Recognizing and resolving ruptures in the therapeutic alliance. In P. Gilbert \& R. L. Leahy (Eds.), The therapeutic relationship in the cognitive behavioral psychotherapies (pp. 90-105). East Sussex: Routledge.

Kirmayer, L. J., Groleau, D., Looper, K. J., \& Dao, M. D. (2004). Explaining medically unexplained symptoms. Canadian Journal Of Psychiatry. Revue Canadienne De Psychiatrie, 49(10), 663-672.

Kleinstäuber, M., Witthöft, M., \& Hiller, W. (2010). Efficacy of short-term psychotherapy for multiple medically unexplained physical symptoms: A metaanalysis. Clinical Psychology Review, 31, 146-160. doi:10.1016/j.cpr.2010.09.001 Kroenke, K. (2007). Efficacy of treatment for somatoform disorders: A review of randomized controlled trials. Psychosomatic Medicine, 69(9), 881-888. doi:10.1097/PSY.0b013e31815b00c4

Lincoln, Y. S., \& Guba, E. G. (1985). Naturalistic Enquiry. Beverley Hills: Sage. 
Luca, M. (2011). Therapeutic activities and psychological interventions by cognitive behavioural and psychodynamic therapists working with medically unexplained symptoms: A qualitative study. Counselling and Psychotherapy Research, 1-10. doi:10.1080/14733145.2011.605455

Luyten, P., van Houdenhove, B., Lemma, A., Target, M., \& Fonagy, P. (2012). A mentalization-based approach to the understanding and treatment of functional somatic disorders. Psychoanalytic Psychotherapy, 26(2), 121-140.

doi:10.1080/02668734.2012.678061

Luyten, P., Van Houdenhove, B., Lemma, A., Target, M., \& Fonagy, P. (2013). Vulnerability for functional somatic disorders: A contemporary psychodynamic approach. Journal of Psychotherapy Integration, 23(3), 250-262.

doi:10.1037/a0032360

McLeod, J. (2001). Developing a research tradition consistent with the practices and values of counselling and psychotherapy: Why counselling and psychotherapy research is necessary. Counselling \& Psychotherapy Research, 1(1), 3-11. doi:10.1080/14733140112331385188

Nettleton, S. (2006). 'I just want permission to be ill': Towards a sociology of medically unexplained symptoms. Social Science \& Medicine, 62(5), 1167-1178. doi:10.1016/j.socscimed.2005.07.030

NHS England (2016a) Implementing the five year forward view for mental health. Retrieved from https://www.england.nhs.uk/wp-content/uploads/2016/07/fyfv-mh.pdf NHS England (2016b). Mental Health: Introduction to and supporting documentation for Value based transformation funding selection. Retrieved from: 
https://www.england.nhs.uk/wp-content/uploads/2016/12/mental-health-call-tobid.pdf

Patton, M. Q. (1999). Enhancing the quality and credibility of qualitative analysis. . Health Services Research, 34, 1189-1208

Rief, W., \& Broadbent, E. (2007). Explaining medically unexplained symptomsmodels and mechanisms. Clinical Psychology Review, 27(7), 821-841. doi:10.1016/j.cpr.2007.07.005

Roth, A. D., \& Pilling, S. (2015). A competence framework for psychological interventions with people with persistent physical health conditions. Retrieved from: https://www.ucl.ac.uk/pals/research/cehp/researchgroups/core/pdfs/Physical_Health_Problems/Physical_Background_Doc.pdf Rubin, J., \& Wessely, S. (2006). The role of stress in the etiology of medically unexplained syndromes. In B. B. Arnetz \& R. Ekman (Eds.), Stress in health and disease. (pp. 292-306). Weinheim Germany: Wiley-VCH Verlag GmbH \& Co KGaA.

Salmon, P. (2007). Conflict, collusion or collaboration in consultations about medically unexplained symptoms: The need for a curriculum of medical explanation. Patient Education and Counseling, 67(3), 246-254. doi:10.1016/j.pec.2007.03.008

Strauss, A. \& Corbin, J. (1990). Basics of qualitative research (Vol. 15): Newbury Park, CA: Sage Publications Inc.

Strauss, A., \& Corbin, J. (1998). Basics of qualitative research: Techniques and procedures for developing grounded theory (2nd ed.). Thousand Oaks, CA, US: Sage Publications, Inc. 
Strassnig, M., Stowell, K. R., First, M. B., \& Pincus, H. A. (2006). General medical and psychiatric perspectives on somatoform disorders: Separated by an uncommon language. Current Opinion in Psychiatry, 19(2), 194-200.

doi:10.1097/01.yco.0000214348.38787.d3

Strauss, A. (1987). Qualitative analysis for social scientists. New York, NY, US: Cambridge University Press.

Taylor, R. E., Mann, A. H., White, N. J., \& Goldberg, D. P. (2000). Attachment style in patients with unexplained physical complaints. Psychological Medicine: A Journal of Research in Psychiatry and the Allied Sciences, 30(4), 931-941. doi:10.1017/s0033291799002317

Timmer, B., Bleichhardt, G., \& Rief, W. (2006). Importance of Psychotherapy motivation in patients with somatization syndrome. Psychotherapy Research, 16(3), 348-356. doi:10.1080/10503300500485292

Tryon, G. S., Blackwell, S. C., \& Hammel, E. F. (2007) A meta-analytic examination of client-therapist perspectives of the working alliance, Psychotherapy Research, 17:6, 629-642, DOI: 10.1080/10503300701320611

Vygotsky, L. S. (1978). Mind in society: The development of higher mental process. Cambridge, MA: Harvard University Press

Warner, A., Walters, K., Lamahewa, K., \& Buszewicz, M. (2017). How do hospital doctors manage patients with medically unexplained symptoms: a qualitative study of physicians. Journal of the Royal Society of Medicine, 110(2), 65-72. doi:10.1177/0141076816686348 
Witthöft, M., \& Hiller, W. (2010). Psychological approaches to origins and treatments of somatoform disorders. Annual Review of Clinical Psychology, 6, 257-283. doi:10.1146/annurev.clinpsy.121208.131505

Wood, D., Bruner, J. S., \& Ross, G. (1976). The role of tutoring in problem solving*. Journal of child psychology and psychiatry, 17(2), 89-100.

Willig, C. (2001) Introducing qualitative research in psychology: adventures in theory and method (1st Edition ed.). Buckingham: Open University Press.

Willig, C. (2010). Introducing qualitative research in psychology: adventures in theory and method (2nd ed.). Maidenhead: McGraw-Hill Open University Press.

Witthöft, M., \& Hiller, W. (2010). Psychological approaches to origins and treatments of somatoform disorders. Annual Review of Clinical Psychology, 6, 257-283. doi:10.1146/annurev.clinpsy.121208.131505

Yon, K., Habermann, S., Rosenthal, J., Walters, K. R., Nettleton, S., Warner, A., . . Buszewicz, M. (2017). Improving teaching about medically unexplained symptoms for newly qualified doctors in the UK: findings from a questionnaire survey and expert workshop. BMJ Open, 7(4). e014720. doi: 10.1136/bmjopen-2016-014720 


\section{Table 1:}

\section{Participant Summary Table}

\begin{tabular}{|c|c|c|c|}
\hline $\begin{array}{l}\text { Participant } \\
\text { pseudonym }\end{array}$ & Core profession & $\begin{array}{l}\text { Years since } \\
\text { qualification }{ }^{1}\end{array}$ & Additional training ${ }^{1}$ \\
\hline 'Anna' & Mental Health Nurse & 20 & $\begin{array}{l}\text { Psychoanalytic Psychotherapist (in } \\
\text { training) }\end{array}$ \\
\hline ‘John’ & Counselling Psychologist & 5 & - \\
\hline 'Freya' & Clinical Psychologist & 4 & $\begin{array}{l}\text { Psychoanalytic Psychotherapist (in } \\
\text { training) }\end{array}$ \\
\hline ‘Debbie’ & Clinical Psychologist & 5 & $\begin{array}{l}\text { Psychoanalytic Psychotherapist (in } \\
\text { training) }\end{array}$ \\
\hline ‘Emma’ & Mental Health Nurse & Not known & $\begin{array}{l}\text { Psychoanalytic Psychotherapist } \\
\text { (qualified) }\end{array}$ \\
\hline 'Rebecca' & Counselling Psychologist & 1 & - \\
\hline ‘Harry’ & Social Worker & 20 & Psychoanalyst (qualified) \\
\hline ‘Katy’ & $\begin{array}{l}\text { Psychodynamic } \\
\text { Counsellor }\end{array}$ & 5 & - \\
\hline ‘Ella’ & Clinical Psychologist & 2 & Systemic training (completed) \\
\hline
\end{tabular}

Note $^{1}$ : At the time the interview was conducted 


\section{Table 2:}

\section{Overview of Model Categories}

\begin{tabular}{|c|c|c|}
\hline Category & Category & Category label \\
\hline Number & Type & \\
\hline Category 1 & Context & Primary care system orientation to MUS \\
\hline Category 2 & Context & Service orientation to MUS \\
\hline Category 3 & Context & Patient orientation to therapy for MUS \\
\hline Category 4 & Context & Clinical orientation to therapy for MUS \\
\hline Category 5 & Process & Drawing in patients by engaging the medical system \\
\hline Category 6 & Process & Meeting patients where they're at \\
\hline Category 7 & Process & $\begin{array}{l}\text { Nudging patients forwards to think about the mind and the body } \\
\text { and the links between them }\end{array}$ \\
\hline
\end{tabular}




\section{Engagement Context}

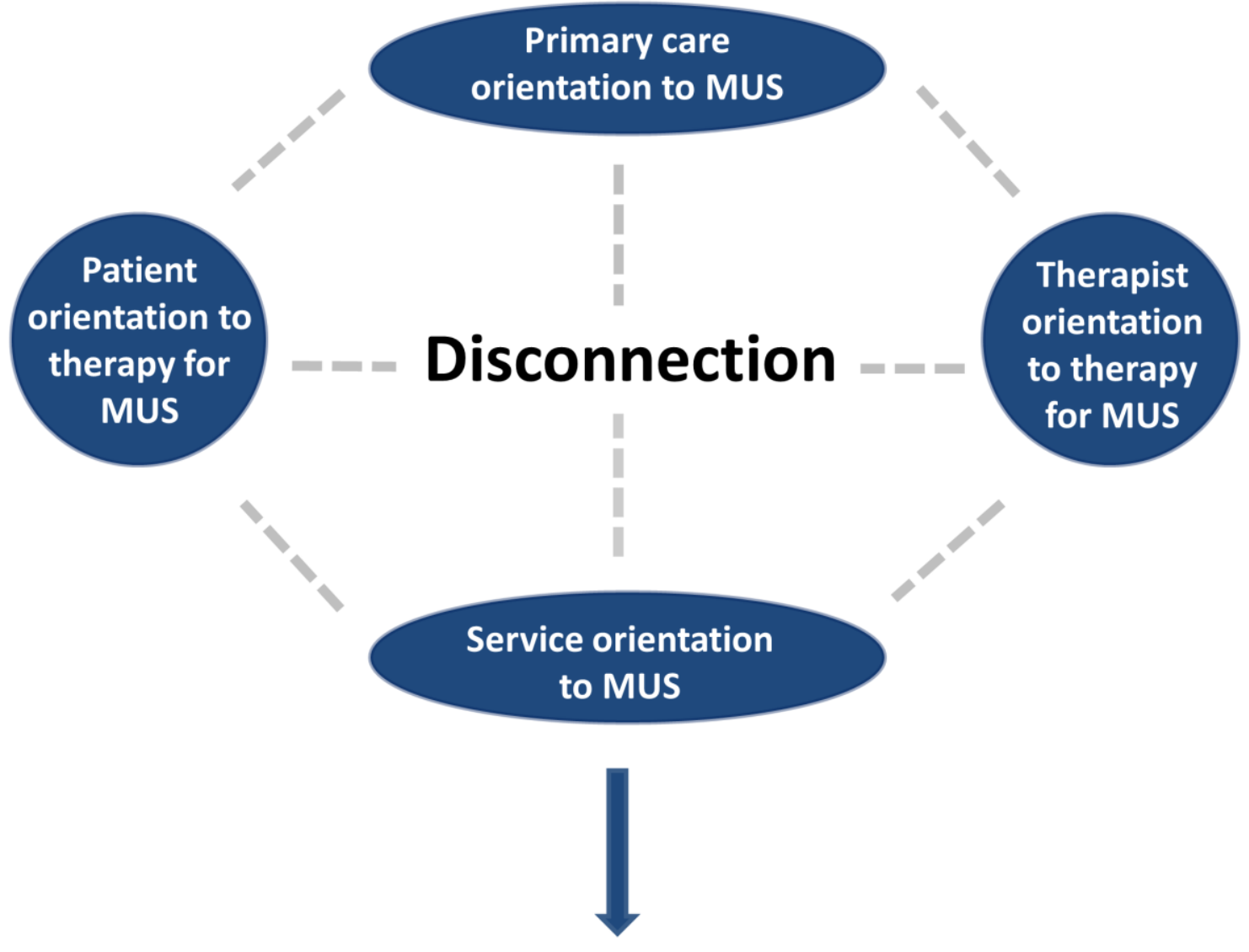

\section{Engagement Process}

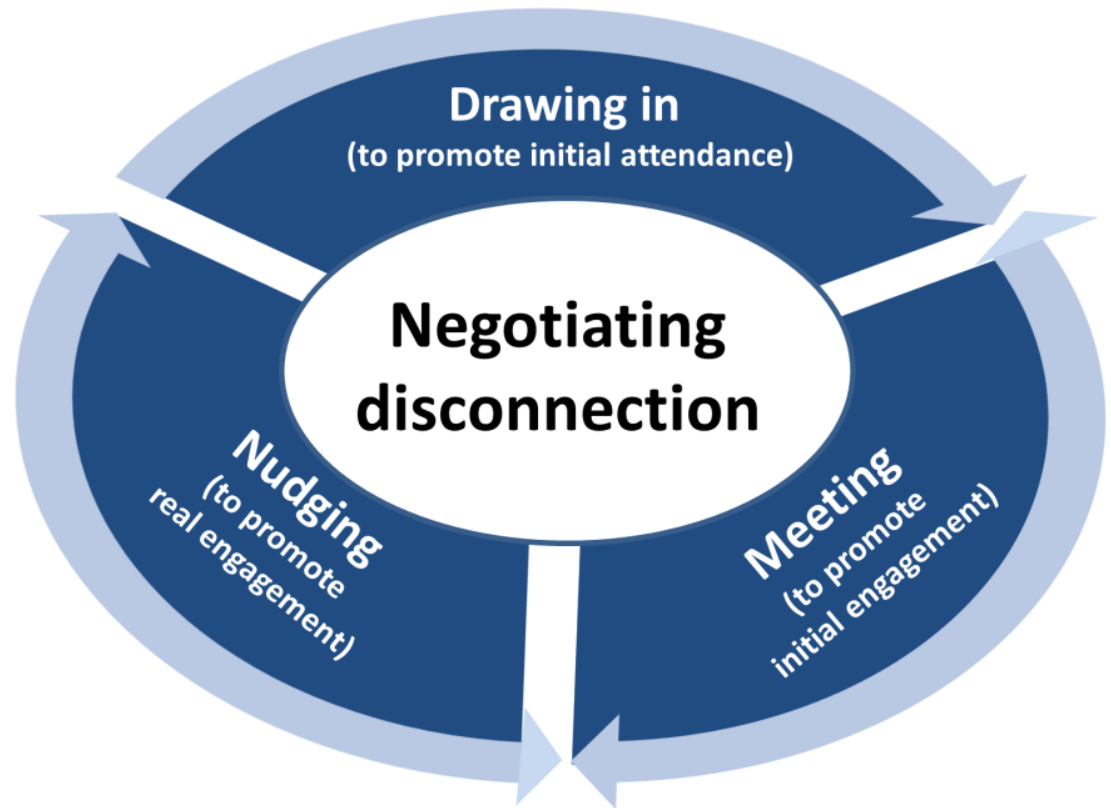

Figure 1: Diagrammatic representation of a model of therapeutic engagement processes for patients who present with medically unexplained physical symptoms 